\title{
Regional tourism competitiveness using the PROMETHEE approach
}

\author{
Ana Paula F. Lopes ${ }^{\mathrm{a}}$, María M. Muñoz ${ }^{\mathrm{b}, *}$, Pilar Alarcón-Urbistondo ${ }^{\mathrm{c}}$ \\ ${ }^{a}$ Polytechnic of Porto (P.Porto)/ISCAP - CEOS.PP. Rua Jaime Lopes Amorim, s/n, 4465-004 S. Mamede de Infesta, Portugal \\ ${ }^{\mathrm{b}}$ Universidad de Málaga, Departamento de Economía Aplicada (Matemáticas), Facultad de Comercio y Gestión, Ampliación Campus de Teatinos, \\ 29071 Málaga, Spain \\ ' Universidad de Málaga, Departamento de Economía y Administración de Empresa, Facultad de Comercio y Gestión, Ampliación Campus de Teatinos, \\ 29071 Málaga, Spain
}

\section{A R T I C L E I N F O}

Associate Editor: Scott McCabe

Keywords:

Destination competitiveness

Competitiveness Index

PROMETHEE-GAIA

Multi-criteria decision making

\begin{abstract}
A B S T R A C T
The competitiveness of tourism destinations is a key issue because it enables destinations to know their position with regard to their competitors. The aim of this paper is threefold: (1) to address the measurement of the competitiveness of tourism destinations at the regional level, (2) to show the suitability of using multi-criteria techniques to measure competitiveness, and (3) to apply the PROMETHEE and GAIA methods within a competitiveness study of eight tourist destinations located in the Northern Region of Portugal. The Metropolitan Area of Porto is the first in the ranking, followed by Cávado and Douro. The results of such an analysis show the comparative strengths and weaknesses of destinations, and allow them to identify their true competitors as well as those other destinations that are most similar to them.
\end{abstract}

\section{Introduction}

The competitiveness of tourism destinations plays a key role in tourism marketing. If a particular destination is not viewed as prominent by potential clients, there can be negative consequences, ranging from increased direct competition to an ambivalent or erroneous perception of the opportunities offered by the destination (Cakmak \& Isaac, 2012). To this end, accurate assessment of the competitiveness of tourism destinations is vital. Many proposals have been made to improve measures of destination competitiveness (Mendola \& Volo, 2017). Nevertheless, there is no clear consensus.

Although some interesting proposals have been made, the recommendations of official bodies and offered in the literature present challenges. Mendola and Volo (2017) state that one of the main concerns is the wide variety of destinations and markets, which limits the development of any measures, in terms of both approach and empirical application. Some authors have therefore opted to focus on a homogeneous set of destinations (Croes \& Kubickova, 2013).

Most of the proposals made by institutions and found in the literature have been implemented on a national scale (Marti \& Puertas, 2016; Webster \& Ivanov, 2014) and there are few projects at a regional or local level (Garín-Muñoz \& Moral, 2016; Sánchez \& López, 2015). This is noteworthy because there is also competition among regional destinations, and even more so among similar or neighbouring regions. For this reason, a regional approach is required, to facilitate the comparison of regions and ultimately increase their competitiveness. The growing interest of institutions such as Exceltur in Spain, which compiles the Urbantur and Monitur reports, and MTur in Brazil in regional measures endorses this view.

This paper is set in the context of this debate and focuses on the analysis of competitiveness at a regional level. In addressing competitiveness among similar and neighbouring regional destinations, both the measurement criteria and the methodology must be

\footnotetext{
* Corresponding author.

E-mail addresses: aplopes@iscap.ipp.pt (A.P.F. Lopes), mmartos@uma.es (M.M. Muñoz), pilar.alarcon@uma.es (P. Alarcón-Urbistondo).
} 
clearly defined. Many proposals have been made by official bodies and in the literature regarding the criteria to be used to measure competitiveness. One of the most acclaimed measures has been the Tourism and Travel Competitiveness Index, which is compiled by the World Economic Forum and seeks to measure the factors and policies that make both the travel and the tourism sectors attractive in different countries or tourist destinations worldwide (Crotti \& Misrahi, 2015). In general, it is widely praised for its comprehensive nature, in terms both of the range of variables covered and of its grouping or dimensionality (Marti \& Puertas, 2016; Webster \& Ivanov, 2014; Wu, Lan, \& Lee, 2012). For this reason, it will be our starting point and the criteria will be applied to specific regions.

With regard to the methodology employed, recent efforts have been geared towards the use of composite indicators to measure competitiveness, as these better reflect its multifaceted and holistic nature (Blanke, Chiesa, Crotti, \& The travel, 2013; Croes \& Kubickova, 2013). Public institutions such as the World Economic Forum and the United Nations World Tourism Organization have chosen this approach and measure the competitiveness of tourism destinations based on indicators that rely on very simple methodologies, usually arithmetic means, where different indicators are given equal weight. For this reason, even though the Tourism and Travel Competitiveness Index has been praised for its criteria, much of the current literature focuses on the methodological improvement of these indicators (Pulido-Fernández \& Rodríguez-Díaz, 2016; Wu et al., 2012). A comprehensive methodology is proposed which ranges from linear regression (Sánchez \& López, 2015) to gravity equations (Marti \& Puertas, 2016), and the use of multi-criteria decision-making techniques as TOPSIS (Zhang, Gu, Gu, \& Zhang, 2011). Most of these methodologies propose either an individual assessment or a comparative ranking system (Marti \& Puertas, 2016; Zhang et al., 2011; Zhou, Maumbe, Deng, \& Selin, 2015). These results enable the measurement of competitiveness (and thus the comparison of destinations) and sometimes also the measurement of distances between destinations in relation to competitiveness. Maps are less often used and it is rarely possible to see the effect that classification dimensions and criteria have on the end result (Zhang et al., 2011). As Mendola and Volo (2017) rightly point out, there is still room for improvement in the methodology of competitiveness evaluation.

The measurement technique set out in the present paper aims to be more comprehensive and to go beyond simply applying a measurement or ranking system to regional destinations. It provides more detailed information, such as distance, the degree of comparability and similarity between destinations, and their strengths and weaknesses. This enables the provider to know the level of competitiveness, the distance between destinations, the most similar and different regions, as well as their shared variables. For this reason, taking into account the multifaceted nature of competitiveness, we propose the use of the multi-criteria Preference Ranking Organization Method for Enrichment of Evaluations (PROMETHEE). Like any other discrete multi-criteria method, it allows us to evaluate and rank destinations, but it also identifies the distances between regions, detects which variables cause such positioning, and analyses similarities and differences between destinations. The analysis is completed through the Geometrical Analysis for Interactive Assistance (GAIA) plane.

This assessment has been carried out in the Northern Region of Portugal, an area in which tourism has become extremely important and which attracts an increasing number of tourists, resulting in increased economic output. For this reason, it is hoped that the region will rank high in competitiveness by using strategic planning that will take full advantage of its potential. However, tourism managers are aware that tourism development in the region is not homogeneous. Therefore, a study of tourism destination competitiveness is required and will help to design medium-term and long-term strategies that will improve the positioning of the region.

The contributions of this paper are thus threefold: (i) to examine the appropriateness of using the Tourism and Travel Competitiveness Index as a competitiveness analysis tool at the regional (non-national) level, (ii) to design a more comprehensive diagnostic and evaluation tool for tourism destination competitiveness and (iii) to apply the proposed methodology in a study of tourism destination competitiveness in the Northern Region of Portugal.

Before presenting our empirical analysis, we will take a closer look at both the Tourism and Travel Competitiveness Index, on which we have based our criteria, and at the PROMETHEE method we have used for our competitiveness assessment. We will then briefly describe the Northern Region of Portugal, where our empirical study was carried out, before presenting that study and its results in Sections "Proposal of criteria and methodology to measure regional tourism competitiveness" and "Results".

\section{Tourism destination competitiveness and its measurement}

Due to the complexity and multidimensionality of the concept of competitiveness, numerous proposals for measuring it have been made, in terms of both tools and methods (Gomezelj \& Mihalič, 2008). Among these, the proposals of Crouch and Ritchie (Crouch \& Ritchie, 1999; Ritchie \& Crouch, 2003) and those of Dwyer, Livaic, and Mellor (2003) stand out, and have been followed by many other authors.

A general classification of the studies that have been inspired by these models leads us to differentiate among the proposals that measure tourism destination competitiveness using qualitative (soft) or quantitative (hard) data, those that employ a supply/demand criterion, and those which apply both methods. In the first category we have studies that use soft data such as surveys on tourists' opinions and perceptions or hard data to measure tourism destination competitiveness; examples include Craigwell and De Lisle (2008), Croes (2011), Zhang et al. (2011) and Zhang and Jensen (2007). From the supply and demand perspective, the literature includes mixed proposals (Craigwell, 2007; Croes, 2011) as well as proposals concerning only supply or only demand. Proposals centred on supply focus on the product as a key aspect to improve competitiveness (Melián-González \& García-Falcón, 2003; Sánchez \& López, 2015; Zhang \& Jensen, 2007), while authors who concentrate on the demand perspective (Bahar \& Kozak, 2007; Caber, Albayrak, \& Matzler, 2012) consider that marketing is a decisive factor in the measurement of tourism destination competitiveness.

Nowadays, many authors consider that the Tourism and Travel Competitiveness Index, published in the Travel and Tourism Competitiveness Report of the World Economic Forum since 2007, is the most complete measure (Ivanov \& Webster, 2013; Marti \& 
Puertas, 2016; Webster \& Ivanov, 2014; Wu et al., 2012). It focuses on measuring the attractiveness of a destination for investment or business development in the travel and tourism sector. In the 2017 report, the Tourism and Travel Competitiveness Index was used to analyse 136 countries (World Economic Forum, 2018). The Index is also popular among tourism promoters and managers, who have used it as a model (Exceltur, 2016, 2017) or in their diagnoses, as is the case with Spain and its National Tourism Plan (Secretaría de Estado de Turismo. Gobierno de España, 2011).

The Index measures tourism competitiveness at country level by building a synthetic indicator, organized into four "subindexes": (1) enabling environment; (2) tourism and travel policy and enabling conditions; (3) infrastructure; and (4) natural and cultural resources. These four subindexes are divided into 14 pillars with a total of 90 individual indicators. Although the Index has been highly praised, it has also been criticized for including data obtained from surveys (soft data), and for the arbitrary weighting of the pillars and indicators (Pulido-Fernández \& Rodríguez-Díaz, 2016) as well as the simplicity of their calculation (Wu et al., 2012).

In addition, the Tourism and Travel Competitiveness Index is designed to measure the competitiveness of countries, not of regions. Similarly, many fewer studies examine the regional level than address destination competitiveness at the national level (Garín-Muñoz \& Moral, 2016; Sánchez \& López, 2015; Zhang et al., 2011; Zhou et al., 2015). This is a striking omission, because regions often play a key role as tourist destinations and many have had competencies in the area of tourism management transferred to them (Garín-Muñoz \& Moral, 2016). The few papers which do focus on the tourism competitiveness of regional destinations draw on proposals at the national level (Sánchez \& López, 2015, Zhang et al., 2011) and assume that such proposals are comprehensive and can be applied to other types of destinations. Nevertheless, some authors have used new "pillars" which take new aspects into consideration, as is the case with Garín-Muñoz and Moral (2016), who assessed "economic results".

With regard to the methodologies used to measure competitiveness, most studies have focused on constructing simple or composite indicators (Blanke et al., 2013; Croes \& Kubickova, 2013). However, as Croes (2011) argues, the methodological construction of these indicators is generally either inappropriate or confusing. The most frequently encountered problems are the methods for dealing with missing data, arbitrary weighting and correlation among the variables, which leads to overestimation and unsound results (Mendola \& Volo, 2017). Moreover, the multidimensionality of the concept of destination competitiveness points to the use of methods such as multi-criteria techniques.

\section{The PROMETHEE method}

The use of multi-criteria techniques to evaluate the competitiveness of tourism destinations has previously been suggested in the literature. Thus, Botti and Peypoch (2013) used the ELECTRE outranking method to assess some Hawaiian islands in terms of competitiveness; Pulido-Fernández and Rodríguez-Díaz (2016) used the Double Reference Point method to calculate the Tourism and Travel Competitiveness Index; and Zhang et al. (2011) proposed the use of a combination of multi-criteria methodologies (entropy to obtain the weights and TOPSIS for ranking) for the Tourism and Travel Competitiveness Index.

PROMETHEE also belongs to the family of outranking methods. First developed by Brans (1982), there have been several interesting applications of PROMETHEE, such as Tourism, Management, Logistics, or Financial Applications, as we can see on the online bibliographical database available at http://biblio.promethee-gaia.net. With regard to tourist destinations, the PROMETHEE method has been used to measure destination performance in several studies (Zopounidis, Baourakis, \& Niklis, 2010).

In the PROMETHEE method, actions are first compared pair-wise on each criterion according to decision-maker preferences, resulting in local scores. These local scores are then aggregated to global scores, obtaining a partial pre-order rank, PROMETHEE I, or a complete pre-order rank, PROMETHEE II.

Let us consider a problem with a finite set of $m$ possible actions or alternatives, $A=\left\{a_{1}, a_{2}, \ldots, a_{m}\right\}$, which are evaluated on a set of $k$ criteria, $F=\left\{f_{1}, f_{2}, \ldots, f_{k}\right\}$. Suppose, without loss of generality, that all the criteria must be maximized. For each criterion $f_{j}$, $j \in\{1,2, \ldots, k\}$ and for each pair of actions $(a, b)$, the decision-maker (DM) expresses his/her preference using a degree of preference, $P_{j}(a, b), P_{j}(a, b) \in[0,1]$, which indicates the preference of action $a$ in relation over action $b$, based on the difference in their evaluation, $d_{j}(a, b)=f_{j}(a)-f_{j}(b)$. The degree of preference is obtained using a preference function chosen by the DM. Several typical forms have been proposed for the preference function (Brans \& Mareschal, 2005). Depending on the function chosen, some parameters may be required. For example, if the DM selects, for criterion $j$, a linear- function (Fig. 1), then the DM is required to specify

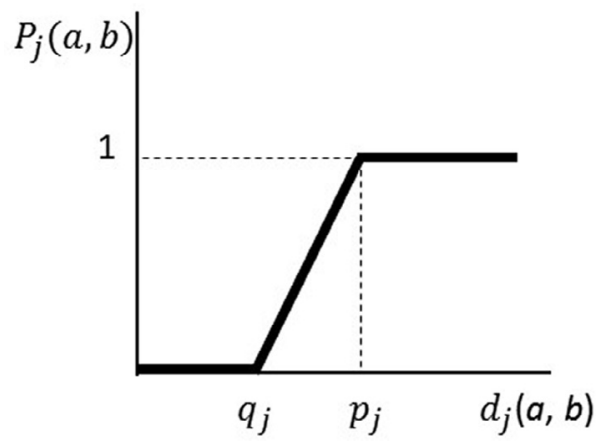

Fig. 1. Preference linear function. 
the threshold values of $p_{j}$ (strict preference) and $q_{j}$ (indifference). Then, if the difference between the evaluation of $a$ and $b$ is smaller than the indifference threshold, $q_{j}$, then neither action is preferred; if the difference between the evaluation of $a$ and $b$ is greater than the preference threshold, $p_{j}, d_{j}(a, b)>p_{j}$, then action $b$ is preferred to action $a$. Formally, the preference function is given by

$$
P_{j}(a, b)=\left\{\begin{array}{c}
0 \text { if } d_{j}(a, b)<q_{j} \\
\frac{d_{j}-q_{j}}{p_{j}-q_{j}} \text { if } d_{j}(a, b)<q_{j} . \\
1 \text { if } d_{j}(a, b)<p_{j}
\end{array}\right.
$$

In order to evaluate how much action $a$ is preferred to $b$ over all criteria, the preference index $\pi(a, b)$ is calculated with a weighted sum of the degrees of preference $P_{j}(a, b)$. The weights, $w_{j}>0$, are positive real numbers that do not depend on the scales of the criteria and represent the importance of each criterion in the decision. That is, the higher the weight, the more important is the criterion:

$$
\pi(a, b)=\sum_{j=1}^{k} P_{j}(a, b) w_{j}
$$

and

$$
\pi(b, a)=\sum_{j=1}^{k} P_{j}(b, a) w_{j}
$$

where $\pi(a, b)$ expresses the degree to which $a$ is preferred over $b$ for all criteria and $\pi(b, a)$ represents how much $b$ is preferred to a. It is obvious that

$$
\left\{\begin{array}{l}
\pi(a, b) \approx 0 \text { implies a weak global preference for a over } \mathrm{b} \\
\pi(a, b) \approx 1 \text { implies a strong global preference for a over } \mathrm{b}
\end{array} .\right.
$$

As each action is compared with other $m-1$ actions, positive $\left(\phi^{+}\right)$and negative $\left(\phi^{-}\right)$outranking flows can be defined as follows:

$$
\begin{aligned}
& \phi^{+}(a)=\frac{1}{m-1} \sum_{x \in A} \pi(a, x) \\
& \phi^{-}(a)=\frac{1}{m-1} \sum_{x \in A} \pi(a, x) .
\end{aligned}
$$

The positive $\phi^{+}(a)$ expresses how alternative $a$ outranks all other $m-1$ alternatives - that is, it represents the global preference for action $a$ in comparison with all the other actions. The higher the value of $\phi^{+}(a)$, the better the alternative is. The negative flow, $\phi^{-}(a)$, expresses how alternative $a$ is outranked by all other $m-1$ alternatives, that is, the global weakness of $a$ in comparison with all the other actions. The smaller $\phi^{-}(a)$, the better the alternative is.

Based on the positive and negative outranking flows, the PROMETHEE I partial ranking is defined as follows:

- a is preferred to b iff $\left\{\begin{array}{l}\phi^{+}(a)>\phi^{+}(b) \text { and } \phi^{-}(a)<\phi^{-}(b) \\ \text { or } \\ \phi^{+}(a)>\phi^{+}(b) \text { and } \phi^{-}(a)=\phi^{-}(b), \\ \text { or } \\ \phi^{+}(a)=\phi^{+}(b) \text { and } \phi^{-}(a)<\phi^{-}(b)\end{array}\right.$

- $\mathrm{a}$ is indifferent to b iff $\phi^{+}(a)=\phi^{+}(b)$ and $\phi^{-}(a)=\phi^{-}(b)$,

- a is non-comparable to b iff $\left\{\begin{array}{l}\phi^{+}(a)>\phi^{+}(b) \text { and } \phi^{-}(a)>\phi^{-}(b) \\ \text { or } \\ \phi^{+}(a)<\phi^{+}(b) \text { and } \phi^{-}(a)<\phi^{-}(b)\end{array}\right.$.

These two flows can be combined to obtain the net outranking flow, defined as follows:

$$
\phi(a)=\phi^{+}(a)-\phi^{-}(a) .
$$

PROMETHEE II provides a complete ranking of actions, from best to worst, and all the alternatives are comparable. The net flow is used to rank the alternatives, through the balance between the positive and negative outranking flows. The higher the value of $\phi(a)$, the better the alternative is.

Net flows are the basis for the Geometrical Analysis for Interactive Aid (GAIA) (Brans \& Mareschal, 2005). GAIA is a visual aid tool used with PROMETHEE that enables visualization and graphical representation of the relative position of the alternatives in terms of contributions to the various criteria. The aim of the GAIA method is to represent in a two-dimensional view, as far as possible, the decision-maker's preferences and their implications. By using principal component analysis, it is possible to obtain the best plane, called the GAIA plane, in which the actions, represented by points, can be projected with the smallest loss of information. The criteria can be represented on this plane by axes, whose length indicates their power of discrimination (importance) in the problem. The position of the criteria indicates the similarity or conflict between them: the smaller the angle, the more similar two criteria are. The weights can also be represented on this plane; the information on the weights is represented in a vector (the decision stick) and 


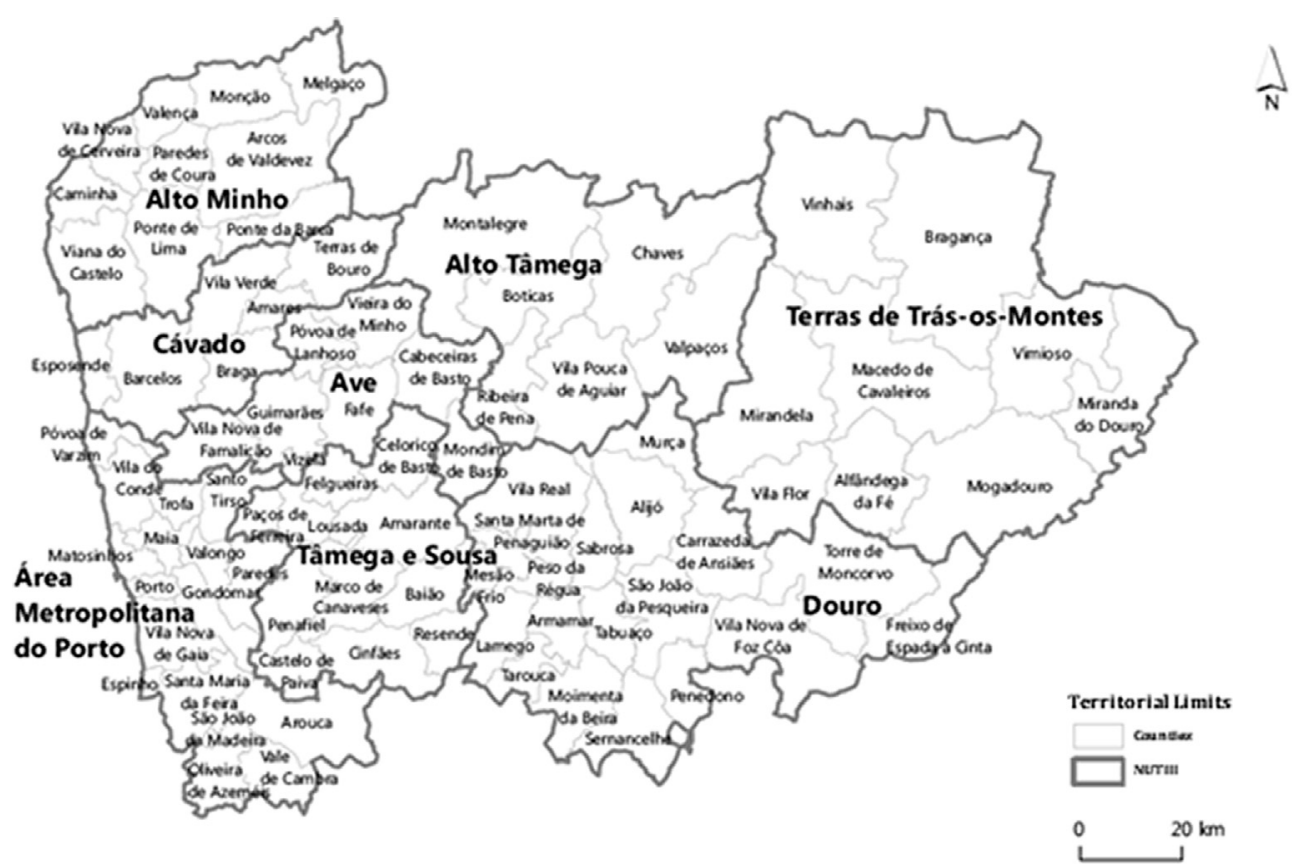

Map 1. Territorial division of NUTS II North Region: NUTS III and Municipalities. Source: (INE, 2015).

represents the decision-maker's priorities.

The GAIA plane offers a visual analysis in which it is readily possible to reach some conclusions: actions located near (far) have similar (dissimilar) performances. The quality of the GAIA representation is given by the delta parameter $(\delta)$, which indicates the quantity of information reflected in the GAIA plane. As a rule of thumb, values larger than $70 \%$ can be considered good: little information is lost and the GAIA plane provides a good, reliable representation of the decision problem.

\section{The Northern Region of Portugal}

Tourism is one of the key sectors in the Portuguese economy and it has become increasingly important in recent years. It is noteworthy that Portugal was ranked in 14th position among 136 countries on the Tourism and Travel Competitiveness Index in 2017. The Portuguese authorities have given priority to the tourism sector, both nationally and at a regional level, which resulted in the approval of the National Strategic Plan for Tourism, launched in 2007 (Ministério da Economia e da Inovação, 2007) and then of the Tourism 2020 plan (Ministério da Economia e do Emprego, 2012). The objective was to consolidate Portugal's position as a leading tourism destination and develop a "new" industry that might contribute to the economic growth of the country. Portugal's vision for tourism is ambitious but realistic, and is centred on three central pillars: high growth, value creation and competitiveness.

Given the importance that tourism has in the Northern Region of Portugal (Map 1), the Region has aspired to reach the top positions in terms of tourism competitiveness through a strategic vision to exploit its potential. With about 3.6 million inhabitants and representing 54\% of the national working population, the Northern Region constitutes almost 35\% of the resident population in Portugal, provides close to $39 \%$ of national exports and accounts for about $29 \%$ of national GDP (INE, 2015). This Region, located in the north-west of the Iberian Peninsula, is characterized by its openness to the outside world, by a strong tradition and experience in international trade and a deep-rooted trend of migration. Entrepreneurial and industrial, young, and considered one of the safest regions, the Northern Region has also taken advantage of various UNESCO "World Heritage Site" classifications to restore urban, historical and natural areas with strong potential for tourism.

The design of science, technology and innovation policies is mainly a responsibility of the central government, but is partly controlled at a regional level through the Regional Coordination and Development Commissions, which have financial and administrative autonomy and are entitled to implement their own Regional Operational Programs (ROPs) in line with key national policies.

The "Norte 2015" (Comissão de Coordenação e Desenvolvimento Regional do Norte, 2006) report outlined a vision and a strategic plan for the Northern Region between 2007 and 2015, and "Tourism 2020", launched by the Portuguese Government for 2014-2020, is the new action plan for the development of tourism in Portugal. It defines objectives and investment priorities until 2020 for national tourism related to projects supported by EU funds. Both plans identify a wide range of tourist resources in the Northern Region, grouped into eight major tourist areas, each with its own specific type of tourism. Following the nomenclature of territorial units for statistics 3 (NUTS 3) of the European Union, in this paper we analyse the eight sub regions of the Northern Region of Portugal.

According to the Economy and Employment Ministry (2012), all the strategic tourism products have been selected on the basis of 


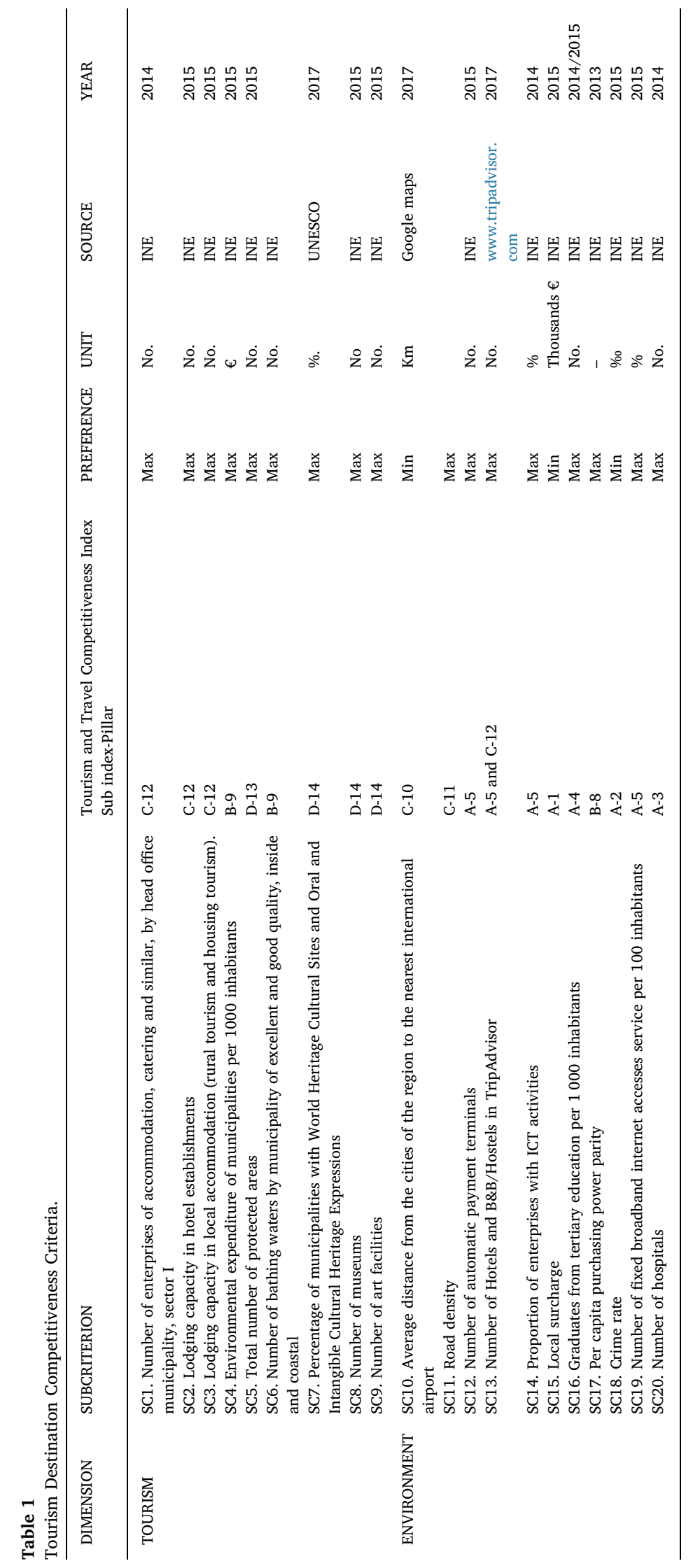


Portuguese resources and distinctive factors, and also in terms of their growth potential. The products with the potential to catalyse short-term growth in the region of Porto and the North are "City Break" and "Touring and Nature Tourism". As well as this, the region also has the potential to offer more structured products in areas like Meetings and Conferences, Health and Wellness and Gastronomy, among others.

\section{Proposal of criteria and methodology to measure regional tourism competitiveness}

To measure the competitiveness of regional tourism, we propose a multidimensional evaluation based on the Tourism and Travel Competitiveness Index and developed to incorporate the PROMETHEE method. The measure initially included all the subcriteria established by the Tourism and Travel Competitiveness Index, and no new criteria, because the Index covers all the dimensions that must be taken into account when measuring competitiveness (Marti \& Puertas, 2016; Webster \& Ivanov, 2014; Wu et al. 2012). Moreover, adding further criteria would result in over-dimensionality problems.

However, we then modified the Index so to include only those criteria/dimensions which are appropriate to the regional level. To this end, we reviewed the criteria with experts responsible for regional tourist destinations (including one from Portugal). As a result, Pillar 7 (International Openness) was omitted since it does not make sense for a regional analysis. Pillar 6 (Prioritization of Travel \& Tourism) was discarded too, because Portugaĺs tourist policy is carried out at a national level. The rest of the subindexes and pillars were retained. Table 1 lists the twenty subcriteria of the modified Index.

We also made an adjustment of a methodical nature and with reference to how we obtain data and their reliability. In the case of Portugal, for some subindexes, such as the Hotel Price Index, there is no breakdown of data at a regional level. After checking that key information had not been lost, we eliminated these subindexes, bearing in mind that the availability, accessibility, reliability, the possibility of comparison and the trustworthiness of the data are crucial in constructing quality indicators (Croes \& Kubickova, 2013). Inferring data directly or indirectly from non-official sources is likely to undermine these factors. As a result, we have worked only with official or widely recognized sources which periodically publish their data and which make it possible to work at a regional level (INE, UNESCO and Google maps). This way, we also hope to guarantee regularity, speed and frequency in the creation and comparison of data over time (Garín-Muñoz \& Moral, 2016). Finally, as the PROMETHEE method works directly with the criteria, from a methodological point of view we can ignore classification by dimensions. In order to facilitate the interpretation of the results, we simply make a distinction between tourism criteria per se and those that refer to the area and the context of the destination.

\section{Tourism criteria}

To measure the basic offer at each destination, we used three subcriteria: the number of businesses at each destination within the hospitality industry (accommodation, catering and similar), and the lodging capacity at each destination, subdivided into hotel establishments and local accommodation (rural tourism and housing tourism).

The complementary offer was measured by examining both the natural environment and the cultural offer. The first aspect was evaluated using three subcriteria: the environmental expenditure per 1000 inhabitants at each destination, the total number of protected areas and the total number of good-quality bathing waters in each municipality. The cultural aspect was measured using three indicators: the percentage of municipalities with UNESCO World Heritage Cultural Sites or Oral and Intangible Cultural Heritage Expressions; the number of museums; and the number of art facilities.

\section{Environment criteria}

The influence of the destination's environment can be analysed using a wide range of indicators (Wu, 2011; Zhang et al., 2011) but there is no consensus on how to measure it. Inspired by the Tourism and Travel Competitiveness Index, we selected four types of key indicator to gauge the influence of the environment: accessibility, business, economic and social indicators.

Accessibility measures ease of access to the destination and has been measured using three criteria: arrival, use/shopping and Information and Communication Technology (ICT). For the first aspect, arrival, we used two indicators: distance to the nearest international airport and road density. The first indicator was measured using the average distance (obtained from Google Google Maps, 2017) from the cities in each area to Francisco Sá Carneiro airport, located in Porto, the nearest international airport for the destinations. The second arrival indicator is the road density of each destination $\left(\mathrm{km} / \mathrm{km}^{2}\right)$, that is, the ratio of the length of the region's road network to the region's land area. The road network includes all types of road: motorways, highways, main or national roads, as well as secondary or regional and other urban and rural roads. Moreover, we included two more indicators: the number of automatic payment terminals and the number of hotels and B\&B/hostels in TripAdvisor, as a measure of ICT accessibility for tourists before arrival.

Business indicators measure the level of business development in the region and it was evaluated through the proportion of companies with ICT activities, the local surcharge level and the number of persons with tertiary education (i.e. graduates) per 1,000 inhabitants (as a measure of training and development of human resources in the area). The economic level of each area was measured using the per capita purchasing power parity standard of living. As regards social factors, we included the security level, measured through the crime rate, the level of technology at each tourist destination, using the number of fixed broadband internet access services per 100 inhabitants, and the number of hospitals in each area. 
Table 2

Tourism Destination Competitiveness Criteria for North Portugal.

\begin{tabular}{|c|c|c|c|c|c|c|c|}
\hline \multirow{2}{*}{$\begin{array}{l}\text { DIMENSION } \\
\text { TOURISM }\end{array}$} & \multicolumn{2}{|c|}{ SUBCRITERION } & \multirow{2}{*}{$\begin{array}{l}\text { PREFERENCE } \\
\text { Max }\end{array}$} & \multirow{2}{*}{$\begin{array}{l}\text { UNIT } \\
\text { No. }\end{array}$} & \multirow{2}{*}{$\begin{array}{l}\text { SOURCE } \\
\text { INE }\end{array}$} & \multirow{2}{*}{$\begin{array}{l}\text { YEAR } \\
2014\end{array}$} & \multirow{2}{*}{$\begin{array}{l}\text { WEIGHT } \\
0.3\end{array}$} \\
\hline & $\mathrm{T} 1$ & $\begin{array}{l}\text { Number of enterprises of accommodation, catering and similar, } \\
\text { located in the area by head office municipality sector I }\end{array}$ & & & & & \\
\hline & $\mathrm{T} 2$ & Environmental expenditure of municipalities per 1000 inhabitants & Max & $€$ & INE & 2015 & 0.1 \\
\hline & T3 & $\begin{array}{l}\text { Percentage of municipalities with World Heritage Cultural Sites and } \\
\text { Oral and Intangible Cultural Heritage Expressions, }\end{array}$ & Max & No. & UNESCO & 2017 & 0.1 \\
\hline & $\mathrm{T} 4$ & Number of museums & Max & No & INE & 2015 & 0.05 \\
\hline & T5 & Number of art facilities & Max & No & INE & 2015 & 0.05 \\
\hline \multirow[t]{6}{*}{ ENVIRONMENT } & A1 & $\begin{array}{l}\text { Average distance from the cities of the region to the nearest } \\
\text { international airport }\end{array}$ & Min & $\mathrm{Km}$ & Google maps & 2017 & 0.1 \\
\hline & A2 & Road density & Max & $\mathrm{km} / \mathrm{km}^{2}$ & INE & 2015 & 0.1 \\
\hline & B1 & Proportion of enterprises with ICT activities & Max & $\%$ & INE & 2014 & 0.05 \\
\hline & B2 & Number of graduates from tertiary education per 1000 inhabitants & Max & No. & INE & $\begin{array}{l}2014 / \\
2015\end{array}$ & 0.05 \\
\hline & S1 & Crime rate & Min & $\%$ & INE & 2015 & 0.05 \\
\hline & S2 & $\begin{array}{l}\text { Number of fixed broadband internet accesses service per } 100 \\
\text { inhabitants }\end{array}$ & Max & $\%$ & INE & 2015 & 0.05 \\
\hline
\end{tabular}

\section{Results}

In this section we analyse the ranking of the eight destinations in the Northern Region of Portugal, describe the order obtained with PROMETHEE I and II, and present an analysis of the contribution of each criterion to the "flow" (see Section "The PROMETHEE Method") of each destination and the GAIA plane. For the analysis, we used Smart Picker Pro commercial software (www.smartpicker.com), which has a user-friendly graphical interface.

The application of the PROMETHEE method requires the function of preference and the weight associated with each criterion to be set beforehand. To this end, we were assisted by an external expert both to select the linear preference function for all sub-criteria, with indifference $(q)$ and preference $(p)$ levels at 20 per cent and 80 per cent of the range of variation for each sub-criterion respectively, and to assign a weight to each sub-criterion. In the regional tourism context, this task would be carried out by the regional decision-maker, who would in turn be assisted by analysts who know the reality on the ground.

In the first phase of resolution, we considered all the criteria described in Section "Proposal of criteria and methodology to measure regional tourism competitiveness" (Table 1). This initial analysis revealed to us, through the GAIA plane, that some of the criteria provided the same information for the destinations. This is a frequent occurrence in problems of this type: highly correlated indicators can indicate "over-information" on the problem, causing some aspects to be "overvalued" in the study, since they are measured several times, while others remain "undervalued". The GAIA plane, based on principal components analysis, is a useful way to detect these types of issues in a multi-criteria problem. We then carried out an analysis of the existing correlations between criteria, and we found that there was a high correlation among the following criteria: SC1, SC2, SC3, SC6, SC7, SC8, SC9, SC12, SC13, SC17, SC20 (see Table 1).

The next step was to perform several tests with different criteria, under the advice of the tourism expert, looking for the most representative competitiveness criteria for this problem. We decided to reduce the number of criteria to the subcriteria listed in Table 2, five in the tourism dimension (the most representative items to evaluate competitiveness for this area), and six in the environmental dimension. As we can see in Table 2, the weights given to the tourism and environmental dimensions are 0.6 and 0.4 , respectively.

The complete order obtained with PROMETHEE II is based on net flows-that is, the difference between the strengths and the weaknesses of the destination (Table 3). This places the Porto Metropolitan Area in the top position. This indicates that the Porto Metropolitan Area is the most competitive destination and, furthermore, its competitive position is very strong (showing a net flow nine times higher than that of the second destination). It is followed by Cávado, the other destination that has a positive net flow. Douro, Ave and Tâmega e Sousa follow in the ranking, all of them with a negative flow, but close to zero, which indicates a weak

Table 3

Positive, negative and net flows of the destinations.

\begin{tabular}{lllll}
\hline Destination & Destination sort name & Net flow & Positive Flow (Phi + ) & Negative Flow (Phi - ) \\
\hline Porto Metropolitan Area & PMA & 0.54 & 0.60 & 0.05 \\
Cávado & CAV & 0.06 & 0.17 & 0.10 \\
Douro & DOU & -0.01 & 0.16 & 0.17 \\
Ave & AVE & -0.03 & 0.11 & 0.14 \\
Tâmega e Sousa & TSO & -0.07 & 0.11 & 0.17 \\
Alto Minho & AMI & -0.12 & 0.06 & 0.17 \\
Terras de Trás-os-Montes & TTM & -0.14 & 0.10 & 0.24 \\
Alto Tâmega & ATA & -0.24 & 0.02 & 0.26 \\
\hline
\end{tabular}




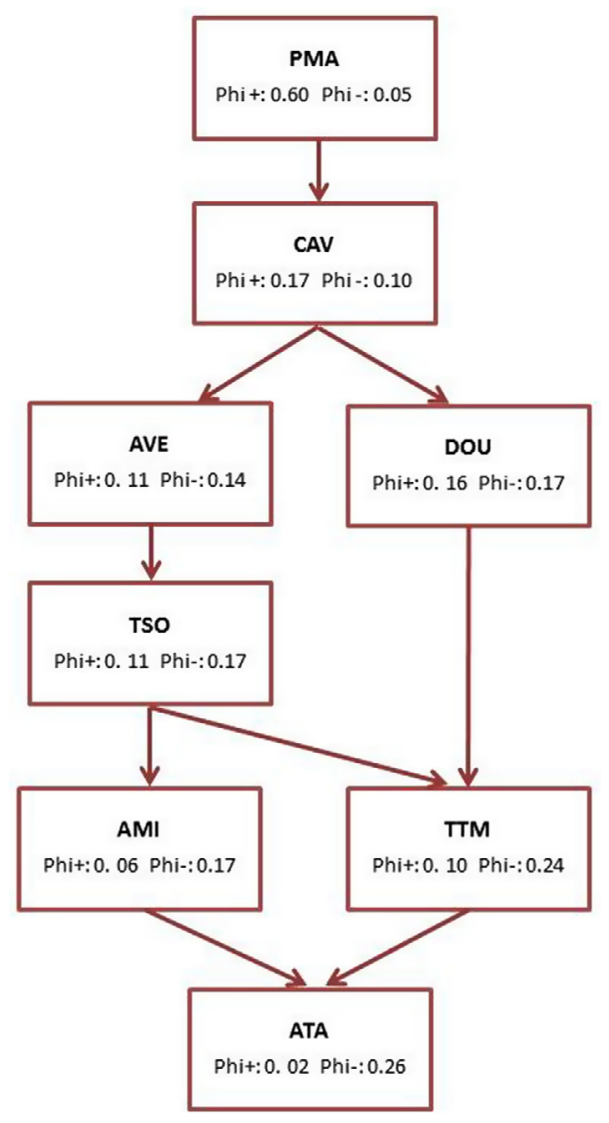

Fig. 2. Outranking graph, PROMETHEE I.

competitive position. The ranking concludes with Alto Minho, Terras de Trás-os-Montes and Alto Tâmega, which are clearly in a disadvantageous position with regard to neighbouring regions due to their comparatively large negative net flows.

The partial order obtained with PROMETHEE I provides a richer interpretation of the ranking, detecting very useful situations which are not comparable, and which enable us to fine tune our positioning strategies. As seen in Fig. 2, the Port Metropolitan Area, the leader among the destinations, is followed by Cávado, which holds a better position than the rest. However, the PROMETHEE I method allows us to see that Ave and Douro contain variables which are not comparable. We cannot say that one is more competitive than the other. This is because the structure of their strengths and weaknesses is different. Moving on, there are two distinct subrankings. Ave ranks above Tâmega e Sousa and Alto Minho, but we cannot say that these two destinations are worse or better than Douro - note that Tâmega e Sousa and Alto Minho present the same negative flow as Douro (0.17). The weakest positions are held by Terras de Trás-os-Montes, which appear as less competitive than Tâmega e Sousa and Douro, and by Alto Tâmega, which is outranked by all destinations.

\section{Similarities and differences between destinations}

The bar chart (Fig. 3) allows us to identify the criteria that determine the strengths and weaknesses of each destination. In addition, we can see whether we are dealing with balanced destinations, such as Cávado, with regions that display particular outstanding positive attributes, like Porto, Douro, Alto Minho and Trás-os-Montes, or with destinations that show clearly negative traits, as is the case with Alto Tâmega, Alto Minho and Terras de Trás-os-Montes.

The GAIA plane (Fig. 4) makes it possible to identify more clearly the similarities between destinations and the strengths and weaknesses of each in relation to one another. In the GAIA plane, the criteria are represented by lines, while the alternatives (destinations) are dots. The delta parameter of the GAIA plane is 74\% (Fig. 4).

The distribution of criteria in the GAIA plane allows us to analyse the concordance between criteria and to better understand the competitive panorama. We can see that there are two groups of tourism criteria: the first group comprises the criteria basic offer (T1), number of museums (T4) and number of art facilities (T5). They all have the same length, which means that their power of discrimination is similar. The second group of tourism criteria includes environmental expenditure (T2) and the UNESCO World Heritage Site criteria (T3), although the axis of T2 is larger than that of T3, which implies that the former has a greater influence than the latter. This is probably an indication that our tourism competitiveness study can be carried out in two different ways. 


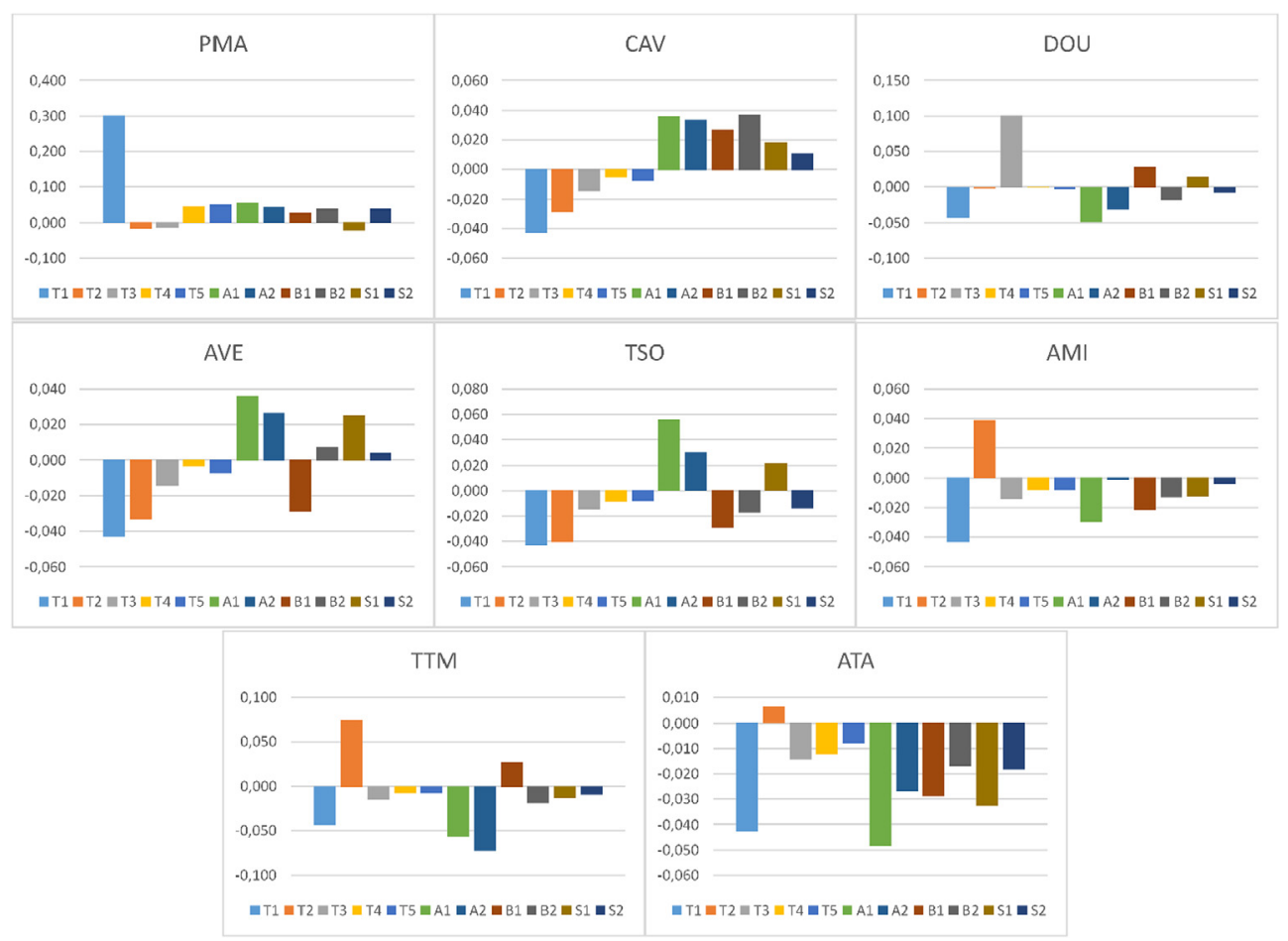

Fig. 3. Bar chart.

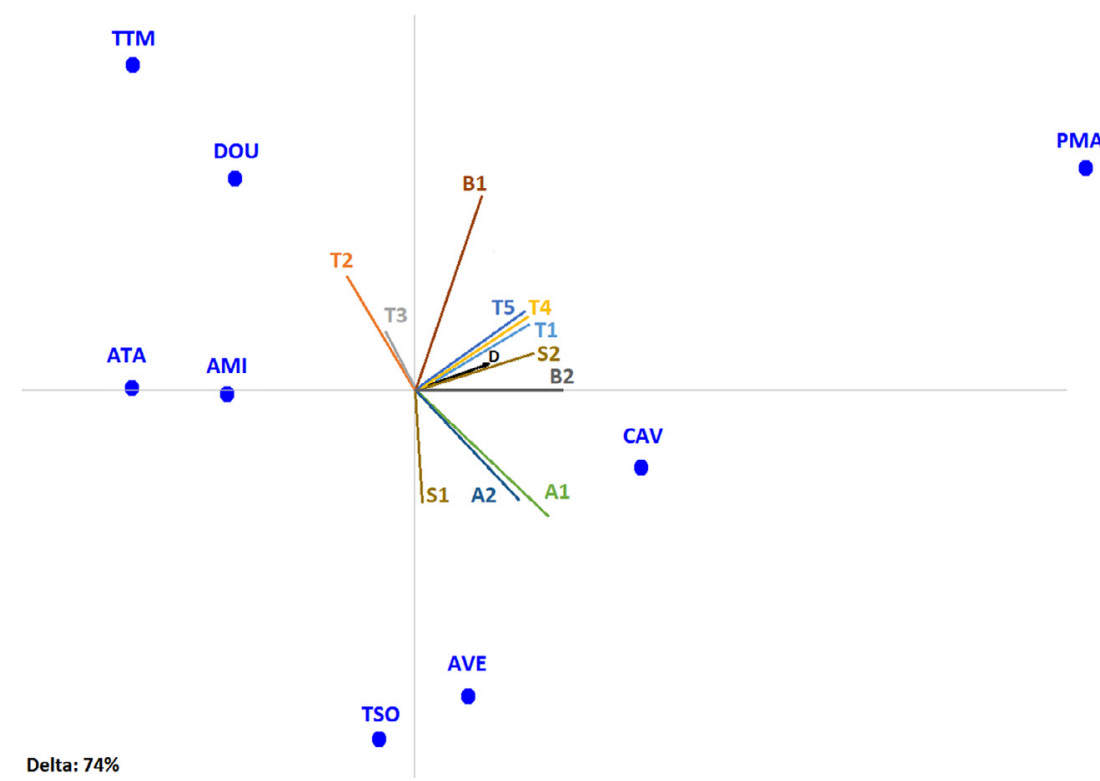

Fig. 4. GAIA plane. Source: Smart Picker Pro.

Likewise, we see that the two accessibility criteria are also very close, which means that they provide the same kind of information. The proportion of university graduates (B2) and the number of internet access (S2) are also very close, that is, the level of education is closely related to the number of access to internet services.

The Porto Metropolitan Area is not only ranked first but also holds a clear and positive position which is very different from the rest (direction of the decision stick (D)). It owes its position to the first group of tourism criteria (basic offer (T1), the number of museums (T4) and the number of art facilities (T5)). However, its weaknesses are environmental expenditure (T2), proportion of municipalities included in the UNESCO World Heritage Site list (T3) and crime rate (S1).

In contrast to the Porto Metropolitan Area, all other destinations rank low in the first group of tourism criteria and are at the 
opposite end of the spectrum from Porto, although there are significant differences among them.

Cávado, the second destination in the ranking, also holds a clearly defined position, scoring high in all the environmental indicators, and low in all the tourism indicators. Its greatest weakness is environmental expenditure (T2).

The other destinations can be grouped into three categories:

- Ave and Tâmega e Sousa score high in airport access (A1) and road accessibility (A2), and have very good values in S1 (crime rate). Ave ranks high on all other indicators, while Tâmega e Sousa scores low in the proportion of university graduates (B2) and the number of internet access services (S2).

- Alto Minho and Alto Tâmega have similar profiles, principally relating to their environmental expenditure (T2). On the remaining criteria both have weaknesses, but these are greater in Alto Tâmega, as can be seen in the bar chart (Fig. 4), and in the GAIA plane, where Alto Minho appears closest to the steering axes of the criteria.

- Douro and Terras de Trás-os-Montes are close in the GAIA plane due to ICT use in business (B1), although Douro is higher in the ranking. This is because they both rank high in ICT use in business (B1), and low in basic offer (T1), air accessibility (A1), number of university graduates (B2) and number of internet access services (S2), showing similar values. The great strength of Douro is the number of municipalities included in the UNESCO World Heritage Site list (T3), while Terras de Trás-os-Montes has the highest score in environmental expenditure (T2).

This map therefore allows us to see regions relative to the clear and strong destination of Porto as the competitive leader. It also allows us to group similar regions. While similar regions may directly compete with one another, there is also the possibility of them joining forces to create better offers and address deficiencies. This last point is especially important in this case because they are destinations that have not yet developed their tourism potential, as evidenced by their low position with regard to basic tourist facilities. For example, Terras de Trás-os-Montes could have a good ally in Duoro, since it could take advantage of its similarity to a destination in a better position in terms of competitiveness (note that they are comparable in PROMETHEE I) and with clear strengths in particular tourist attractions. Moreover, they could improve their basic tourism offer by working together.

Alto Tâmega, which is in a very unfavourable position with respect to the rest in the general ranking and PROMETHEE I, could take advantage of similarity to work with Alto Minho. As well as this, according to PROMETHEE I they are close competitors.

\section{Conclusions}

Our work has three aims: (i) to assess the appropriateness of the Tourism and Travel Competitiveness Index as a competitiveness analysis tool at regional and non-national territorial levels, (ii) to design a wider diagnostic and evaluation tool for the evaluation of tourism destination competitiveness and (iii) to evaluate the destination competitiveness in the Northern Region of Portugal using the proposed methodology.

With regard to the first point, when measuring the competitiveness of regional destinations, the empirical study carried out in the Northern Region of Portugal reveals that the indicators that make up the Tourism and Travel Competitiveness Index are designed for comparisons between countries, and its application to regions requires important adjustments. This is mainly due to two reasons: (1) many of the indicators that make sense at the country level (for example, the degree of openness) do not make sense at a regional level; and (2) some of the indicators contained in the Index do not have a breakdown at the regional level in tourism and institutional statistics.

Thus we selected those elements of the Tourism and Travel Competitiveness Index that make sense for this geographical area. However, we are aware that the debate is not closed on which attributes to evaluate, particularly at the regional level. The choice of criteria used here is therefore open to debate. In this regard, a future line of work could be to get closer to the study of regional competitiveness, not by translating the general competitiveness indicators found in the literature, but rather via a specific regional analysis. As well as this, a next step would be to examine the choice of other types of indicators that make sense at the regional level and not at the national level (and are therefore not part of the Tourism and Travel Competitiveness Index). To this end, it is worth mentioning the work of Sánchez and López (2015) on Brasil (MTur), in which the competitiveness of destinations at a regional level is analysed and which is not based on the Tourism and Travel Competitiveness Index.

Regarding the methodology used to calculate the indicator, we have contrasted the most ideal methodology found in most of the literature on the subject with that used by public entities. Specifically, PROMETHEE leads us to agree with authors such as PulidoFernández and Rodríguez-Díaz (2016) on the need to give the criteria different weights, depending on the relative importance of each sub-criterion. In addition, the chosen tools allowed us, in the initial phase, to validate and refine indicators, discovering which aspects of competitiveness are over- or under-dimensioned, and therefore over- or undervalued. This avoids the "overvaluation" of some destinations (those that are strong in the aspects measured more than once) and the "undervaluation" of others. This opens up another interesting line of study: the identification of redundant variables within the Tourism and Travel Competitiveness Index at the country level. This would simplify the proposed model and the searching for data sources, as some would no longer be necessary.

One of the advantages is the greater amount of information that this technique supplies. Thus, as well as the traditional ranking that PROMETHE II provides, showing results similar to those obtained when using a synthetic indicator, PROMETHEE I allows us to identify both the leaders of the group and non-comparable realities. It would be a mistake for a manager to identify and be inspired by more competitive destinations when these are essentially non-comparable. The evaluation can be completed with a comparative study which, in a very graphic manner, helps to identify similar regions and analyse the positioning of the destinations. In addition, the wide scope of decision-making data enables us to identify the best alternatives. 
Nevertheless, the use of this multi-criteria technique has its limitations. The set of weightings and the functions to determine the thresholds of indifference and preference are common in all cases. This in fact implies that this type of measurement is valid for similar destinations that share contexts or that are under the same decision-making authority. However, it is not uncommon to encounter this limitation when composite indicator methodology is applied to the evaluation of destination competitiveness.

In addition, the question of the weightings given to each criterion opens a new line of study. Initially, it would be interesting if they were given by experts or by the managers themselves, as they reflect the impressions of those who are responsible for the decision-making, and this would make it possible to personalize the indexes according to the managers' vision and requirements. However, the weightings could also be done using mathematical techniques, which would provide more objective results.

For the specific case of the Northern Region of Portugal, the work shows the leadership of the Porto Metropolitan Area, which displays strengths in almost all the indicators and holds a clearly differentiated position. This is expected, since it is the area with the greatest tourist and economic development of those studied and has very sound infrastructure.

The noteworthy poor evaluation of the rest of the destinations in terms of their basic tourism offer indicates that these regions are not very developed. That said, some regions, such as Douro and Alto Minho, offer great advantages in the form of natural or cultural tourist attractions.

Cávado shows weaknesses in the tourism criteria, although its good position with regard to the other criteria enabled it to rank second. Furthermore, its positive and negative criteria are very well balanced, which leads us to consider the potential of the area to grow as a tourist destination if improvement of the tourist indicators is achieved (those that can be improved through public policies or private initiatives).

The rest of the destinations have been classified into three groups. If we analyse GAIA and PROMETHEE I together, we can see allies and real competitors. This is interesting for managers because they can more clearly identify regions that are not very developed for tourism, but which could work together to tackle their deficiencies, many of which are shared. This is the case of Alto Minho, Alto Tâmega or Ave and Tâmega e Sousa. Highlighted here is the position of Douro, which presents the best results with regard to the number of World Heritage cultural sites and of the Oral and Intangible Cultural Heritage criteria, which is the result of its cultural and scenic wealth, but which is deficient in terms of its basic tourism offer, territorial accessibility or technology.

One of the main challenges that we have encountered in transferring a general indicator to the regional level is the lack of data available at this level. On this point, those of us who study this subject should alert and encourage those responsible for tourism management to provide us with a good statistics, broken down into the necessary levels.

Finally, these results should be contrasted with other destinations, in order to shed more light on what is proposed here.

\section{References}

Bahar, O., \& Kozak, M. (2007). Advancing destination competitiveness research: Comparison between tourists and service providers. Journal of Travel \& Tourism Marketing, 22(2), 61-71. https://doi.org/10.1300/J073v22n02.

Blanke, J., Chiesa, T., \& Crotti, R. (2013). The travel \& tourism competitiveness index 2013: Contributing to national growth and employment. In J. Blanke, \& T. Chiesa (Eds.). The travel \& tourism competitiveness report 2013: Reducing barriers to economic growth and job creation (pp. 3e41). Geneva: World Economic Forum.

Botti, L., \& Peypoch, N. (2013). Multi-criteria ELECTRE method and destination competitiveness. Tourism Management Perspectives, 6, 108-113. https:/doi.org/10. 1016/j.tmp.2013.01.001.

Brans, J., \& Mareschal, B. (2005). PROMETHEE methods. Multiple Criteria Decision Analysis: State of the Art Surveys, $163-186$.

Brans, J. P. (1982). L'ingénierie de la décision: élaboration d'instruments d'aide à la décision. La méthode PROMETHEE. In R. Nadeau, \& M. Landry (Eds.). L'aide à la décision: Nature instruments et perspectives d'avenir. Québec, Canada: Presses de l'Université Laval.

Caber, M., Albayrak, T., \& Matzler, K. (2012). Classification of the destination attributes in the content of competitiveness (by revised importance-performance analysis). Journal of Vacation Marketing, 18(1), 43-56. https://doi.org/10.1177/1356766711428802.

Cakmak, E., \& Isaac, R. K. (2012). What destination marketers can learn from their visitors" blogs: An image analysis of Bethlehem, Palestine. Journal of Destination Marketing \& Management, 1, 124-133. https://doi.org/10.1016/j.jdmm.2012.09.004.

Comissão de Coordenação e Desenvolvimento Regional do Norte (2006). Norte 2015 - Competitividade e Desenvolvimento - Uma Visão Estratégica, Comissão de Coordenação e Desenvolvimento Regional do Norte.

Craigwell, R. (2007). Tourism Competitiveness in Small Island Developing States. UNU-WIDER Working Papers.

Craigwell, R., \& De Lisle, W. (2008). The competitiveness of selected Caribbean tourism markets. Social and Economic Studies, 57(1).

Croes, R. (2011). Measuring and explaining competitiveness in the context of small island destinations. Journal of Travel Research, 50(4), 431-442. https://doi.org/10. $1177 / 0047287510368139$.

Croes, R., \& Kubickova, M. (2013). From potential to ability to compete: Towards a performance-based tourism competitiveness index. Journal of Destination Marketing and Management, 2(3), 146-154. https://doi.org/10.1016/j.jdmm.2013.07.002.

Crotti, R., \& Misrahi, T. (2015). The travel \& tourism competitiveness report 2015 - Growth through shocks. World Economic Forum.

Crouch, G. I., \& Ritchie, J. R. B. (1999). Tourism, competitiveness, and societal prosperity. Journal of Business Research, 44(3), 137-152. https://doi.org/10.1016/ S0148-2963(97)00196-3.

Dwyer, L., Livaic, Z., \& Mellor, R. (2003). Competitiveness of Australia as a tourist destination. Journal of Hospitality and Tourism Management, 10(JANUARY 2006), $60-78$.

Exceltur. (2016). Monitur 2014. Monitor de la competitividad turísticas de las comunidades autónomas. Madrid.

Exceltur. (2017). Urbantur 2016. Monitor de la competitividad turística de los destinos urbanos españoles. Madrid.

Garín-Muñoz, T., \& Moral, M. (2016). Competitividad del Sector Turístico Español. Papeles de Economía Española, 150, $194-209$.

Gomezelj, D. O., \& Mihalič, T. (2008). Destination competitiveness-Applying different models, the case of Slovenia. Tourism Management, 29(2), 294-307. https://doi. org/10.1016/j.tourman.2007.03.009.

Google Maps. (2017). Google Maps.

Ivanov, S., \& Webster, C. (2013). Globalisation as a driver of destination competitiveness. Annals of Tourism Research, 43, 628-633. https://doi.org/10.1016/j.annals. 2013.07.010.

INE, Instituto Nacional de Estatística (2015). Statistical Yearbook of Portugal 2014. Lisboa.

Marti, L., \& Puertas, R. (2016). Determinants of tourist arrivals in European Mediterranean countries: Analysis of competitiveness, (2009).

Melián-González, A., \& García-Falcón, J. M. (2003). Competitive potential of tourism in destinations. Annals of Tourism Research, 30(3), 720-740. https://doi.org/10. 1016/s0160-7383(03)00047-1.

Mendola, D., \& Volo, S. (2017). Building composite indicators in tourism studies: Measurements and applications in tourism destination competitiveness. Tourism 
Management, 59, 541-553. https://doi.org/10.1016/j.tourman.2016.08.011.

Ministério da Economia e da Inovação. (2007). Plano Estratégico Nacional do Turismo (PENT) - Para o desenvolvimento do turismo em Portugal.

Ministério da Economia e do Emprego (2012). Plano Estratégico Nacional do Turismo. Ministerio Da Economia e Do Emprego, 88. https://doi.org/10.1007/s13398-014. 0173-7.2.

Pulido-Fernández, J. I., \& Rodríguez-Díaz, B. (2016). Reinterpreting the World Economic Forum’s global tourism competitiveness index. Tourism Management Perspectives, 20(Supplement C), 131-140. https://doi.org/10.1016/j.tmp.2016.08.001.

Ritchie, J. R. B., \& Crouch, G. I. (2003). The competitive destination, a sustainable tourism perspective. Cambridge: Cabi Publishing.

Sánchez, A. G., \& López, D. S. (2015). Tourism destination competitiveness: The Spanish Mediterranean case. Tourism Economics, 21(6), 1235-1254. https://doi.org/ $10.5367 /$ te. 2014.0405

Secretaría de Estado de Turismo. Gobierno de España. (2011). Plan Nacional e Integral de Turismo 2012-2015.

Webster, C., \& Ivanov, S. (2014). Transforming competitiveness into economic benefits: Does tourism stimulate economic growth in more competitive destinations? Tourism Management, 40, 137-140. https://doi.org/10.1016/j.tourman.2013.06.003.

World Economic Forum. (2018). Travel tourism competitiveness report 2017. https://www.weforum.org/reports/the-travel-tourism-competitiveness-report-2017.

Wu, W. W. (2011). Beyond Travel \& Tourism competitiveness ranking using DEA, GST, ANN and Borda count. Expert Systems with Applications, 38(10), 12974-12982. https://doi.org/10.1016/j.eswa.2011.04.096.

Wu, W. W., Lan, L. W., \& Lee, Y. T. (2012). Critiquing the World Economic Forum's concept of destination competitiveness: A further analysis. Tourism Management Perspectives, 4, 198-206. https://doi.org/10.1016/j.tmp.2012.08.008.

Zhang, H., Gu, C., Gu, L., \& Zhang, Y. (2011). The evaluation of tourism destination competitiveness by TOPSIS \& information entropy - A case in the Yangtze River Delta of China. Tourism Management, 32(2), 443-451. https://doi.org/10.1016/j.tourman.2010.02.007.

Zhang, J., \& Jensen, C. (2007). Comparative advantage. Explaining tourism flows. Annals of Tourism Research, 34(1), 223-243. https://doi.org/10.1016/j.annals.2006. 08.004.

Zhou, Y., Maumbe, K., Deng, J., \& Selin, S. W. (2015). Resource-based destination competitiveness evaluation using a hybrid analytic hierarchy process (AHP): The case study of West Virginia. Tourism Management Perspectives, 15, 72-80. https://doi.org/10.1016/j.tmp.2015.03.007.

Zopounidis, C., Baourakis, G., \& Niklis, D. (2010). International Journal of Information and Decision Sciences. International Journal of Information and Decision Sciences, 2(3), 285-303. https://doi.org/10.1504/IJIDS.2010.033452.

Ana Paula Lopes, aplopes@iscap.ipp.pt, Polytechnic of Porto (P.Porto)/ISCAP - CEOS.PP. Rua Jaime Lopes Amorim, s/n, 4465-004 S. Mamede de Infesta, Portugal has a Ph.D. in Mathematics. She is Associate Professor in ISCAP since 2000. Her main research interests focus are LMS supports platforms, information technologies in education, E-learning teaching, teaching/learning education paradigm, Learning Analytics, Multi Criteria Decision Making.

María M. Muñoz, mmartos@uma.es, is Associate Professor of the Department of Applied Economics (Mathematics), Faculty of Commerce and Management, University of Málaga (Spain). She has published several research papers in scientific journals (such as European Journal of Operational Research, TOP, OR Spectrum, Journal of Optimization Theory and Applications) Her main research interests are multicriteria decision analysis (discrete and continuous methods), stochastic programming and economic applications and constructing composite indicators.

Pilar Alarcón-Urbistondo, pilar.alarcon@uma.es, earned her PhD degree from University of Málaga. She is Associate Professor of the Department of Economics and Business Administration, Faculty of Commerce and Management, University of Málaga (Spain Currently, her research lines are, among other, family vacation decisionmaking, the image of the tourist destinations and the evaluation of the commercial attractiveness of outbound markets. 